\title{
Participating in the Paralympic Games through exercise rehabilitation for individuals with disabilities
}

\author{
Yong-Seok Jee (D) https://orcid.org/0000-0001-6797-0843
}

The 2018 Pyeongchang Winter Paralympic Games were held for 10 days from March 9 to 18, 2018 in Pyeongchang, Gangwon Province, Republic of Korea. This was the first winter paralympic stage in Korea since the 1988 Seoul Paralympic Games.

The Paralympic Games is a major international mega-sport event involving athletes with a range of disabilities, including impaired muscle power (e.g., paraplegia, quadriplegia, muscular dystrophy, post-polio syndrome, and spina bifida), impaired passive range of movement, limb deficiency (e.g., amputation or dysmelia), leg length difference, short stature, hypertonia, ataxia, athetosis, vision impairment, and intellectual impairment (International Paralympic Committee [IPC], 2018). Since the 1988 Summer Games in Seoul, South Korea, the Winter and Summer Paralympic Games, have been held almost immediately following the respective Olympic Games. All Paralympic Games are governed by the IPC (2018).

The Summer Paralympics consist of 22 events and the Winter Paralympics consist of 6 events with several competitions within each event. For example, Alpine skiing is divided into downhill, super combined, super-G, slalom, and giant slalom. The IPC oversees most of the sports games, while other international organizations such as the International Sports Federations, the International Wheelchair and Amputee Sports Federation, the International Blind Sports Federation and the Cerebral Palsy International Sports and Recreation Association manage various others. For the National Paralympic Association and the international sports associations mentioned above, there is a national charter that is re- sponsible for recruiting players and managing events at the national level (Special Olympics, 2006).

The Paralympics has grown from a small gathering of British World War II veterans in 1948 to become one of the largest international sporting events in the early 21 st century. The Paralympics has grown from 400 athletes with disabilities from 23 countries in 1960 to thousands of competitors from over 100 countries in the London 2012 Games (Dehghansai et al., 2017). The etymology of 'paralympics' reveals that it was meant to be held in parallel with the Olympics, as the prefix, 'para' means side by side. However, the present paralympics have deviated from the original meaning of the word. (International Committee of Sports for the Deaf, 1996).

Given the wide variety of disabilities that Paralympic athletes have, there are several categories in which the athletes compete. The allowable disabilities are broken down into ten eligible impairment types as shown in above. These categories are further broken down into classifications, which vary from sport to sport. Sports including any exercise is a popular hobby and also plays an integral part in preparing for games like the Olympics or the Paralympics. The beneficial effects of exercise are continually being discovered and advanced research on more effective methods of exercise are being made to the general or handicapped people (Kim, 2018).

Life satisfaction for those with disabilities is relatively low, especially in terms of economic satisfaction (Stensman, 1985). There is a difference in the quality of life (QoL) satisfaction according to 
educational background and gender. The QoL for people with disabilities with higher education levels is higher than those with lower levels of education. Individuals with visual impairment or physical handicap generally had lower levels of life satisfaction compared to those with other types of disabilities. In addition, the QoL tends to be lower for individuals with more severe grades of disability.

It is possible for people with disabilities to have the same level of life satisfaction as those without disabilities. The only place where the above-mentioned educational background, gender, disability level, and economic status do not act as barriers is the sports scene. In sports, it is possible to make selections preferred by the disabled, make improvements through exercise rehabilitation, and develop professional sports techniques for each sport. Taking the above into consideration, it is possible for a person with a disability to completely start a new life through sports and to improve their QoL. The Paralympic Games should become a mega-sporting venue for everyone with disabilities. Those with disabilities can set an example for others with disabilities by demonstrating their willingness to overcome their challenges.

\section{CONFLICT OF INTEREST}

No potential conflict of interest relevant to this article was reported.

\section{REFERENCES}

Dehghansai N, Lemez S, Wattie N, Baker J. A Systematic review of influences on development of athletes with disabilities. Adapt Phys Activ Q 2017;34:72-90.

International Committee of Sports for the Deaf (ICSD). The World Games for the Deaf and the Paralympic Games [Internet]. Lausanne (Switzerland): ICSD; December 1996 [cited 2018 Apr 2]. Available from: http:// www.ciss.org/.

International Paralympic Committee (IPC). Classification [Internet]. Bonn (Germany): IPC; 2018 [cited 2018 Apr 1]. Available from: http://www. paralympic.org/classification .

Kim CJ. Considering on the exercise rehabilitation and the Journal of Exercise Rehabilitation. J Exerc Rehabil 2018;14:1.

Special Olympics. Special Olympics and the Olympic Movement [Internet]. Washington, DC: Special Olympics; 2006 [cited 2018 Apr 2]. Available from: https://www.specialolympics.org/.

Stensman R. Severely mobility-disabled people assess the quality of their lives. Scand J Rehabil Med 1985;17:87-99.

Research Institute of Sports and Industry Science, Hanseo University, 46 Hanseo 1-ro, Haemi-myeon, Seosan 31962, Korea E-mail: jeeys@hanseo.ac.kr 